\title{
Brief Discussion on Micro-film Creation Art
}

\author{
Jinghua Lv, Huaidong Zhao \\ College of Art, Xi'an University of Architecture and Technology, Xi'an, 710055, China
}

Keywords: Micro-film, Art creation, Value, Idea

\begin{abstract}
With rapid development of culture and art cause, film industry is developing at an alarming rate. To adapt development trend of film industry and creation art change in new media era, micro-film emerges in the crack of television films and advertisements and exists. Continuous leapfrog development of Chinese film industry in the future will certainly drive further development of micro-film creation. This paper analyzes the connotation of micro-films, sets forth the value of micro-film art creation and proposes main idea of micro-film art creation.
\end{abstract}

\section{Introduction}

Micro-film is a new type of films appearing and gradually developing in recent years. The projection duration of micro-films is between $3 \mathrm{~min}$ and $40 \mathrm{~min}$. compared with traditional films, micro-film owns such prominent advantages as conciseness and varied forms. The main contents involve commercial advertisement customization, publicity for public benefit and humor. Micro-films may be shot to series or shot independently. Micro-films uphold personal free expression in the shooting process and can express the dreams of directors which cannot be achieved originally in a very short time. Meanwhile, every creator may freely express what they like by the shot. Thus, micro-films are favored by contemporary young people. Micro-films can be shot via mobile phone and camera. Although the quality of micro-films is not stable enough, they can reflect the passion if young generation. Under fierce competition environment, people can independently micro-films, which can make sure the websites have more participation in profit.

\section{Connotation of micro-films}

Famous film research scholar Krakauer advocates corporeal reality restoration theory during analyzing the essence of films. He gained such opinion when studying film art creation form the perspective of art creator. Since micro-films own art feature, micro-film is consistent with the film in terms of art creation features, and owns very strong artistry. Meanwhile, art characteristic of micro-films is that they give up commercial purpose and improve to human spiritual level. This is the essential connotation of films that film art creators must carefully think. The process of micro-film art creation is actually a practice process of the artistry. Micro-film creators project their own emotions in films in art form and the apply audiences' emotions to make them transform to subjective spirit experience so that audiences' body and mind can be relaxed and generate emotional resonance, just like the director or leading roles in the film who participate in art creation of the story and experience the whole creation process. This deeply reveals the connotation of micro-films.

\section{Value of micro-film art creation}

\section{Carrier to record youth footprint}

If the micro-film is analyzed in a narrow sense, it owns story line, artistry and creative elements and can be well shared. Generally speaking, micro-films spread via modern new media platform in a fast, wide and convenient manner, and may easily influence consumers. For young art creators who create micro-films, their youth can interpret passionate years incisively and vividly. In micro-film works, there are not only the works cherishing the memory of happy campus life and expressing the sentiment of schoolfellows, but also the works longing for and cherishing beautiful love and recording love stories on campus. Meanwhile, there are also encouragement stories revealing 
struggling youth and teamwork spirit. Micro-films can fully reveal such characteristics as micro-duration, micro-cost and micro-production, show the life of young students incisively and vividly and actively lead vast students and teachers for self-service, show themselves and promote cultural connotation of current undergraduates.

\section{Source to enrich campus culture}

Campus culture construction of colleges can very effectively improve various qualities of college students and offer all kinds of service modes for contemporary college students. Meanwhile, it is also an important method for education with culture. All kinds of colleges should actively boost diversification course during constructing campus culture with distinct features so as to facilitate innovation of campus culture service carrier and enhance characteristics of campus culture brand. The education function of campus culture should be highlighted in ideological and political education of college students to as to give full play to the function of fresh troops in cultural construction course. In view of the approval of micro-era, after micro-films gradually rise, brand-new vigor is injected for micro-film creation, development and prosperity. In particular, active cooperation among each department, student union, Youth League Committee and Party Working Committee makes colleges become an important soil to moisten micro-film creation. This greatly contributes to boosting participation and interaction of vast audiences. Compared with film-implanted advertisement and hard advertisement in traditional sense, micro-films can let audiences participate in them and even conduct some interactions. Besides, micro-film creators can apply multiple different methods to improve audiences' participation and interaction. As modern information technology, image technology and media communication become increasingly developed, it is very simple for college students to conceive a new micro-film. They just need a good idea, a new originality, a camera and several student actors. College students prepare the script and perform by themselves. In this process, they freeze-frame beautiful scenery of the college, leave fine youth footprints, show youthful spirit of Chinese youth group and high-spirited outlook.

\section{Effectively promote audiences' speaking right}

Micro-fiction and microblog which have been popular in recent years form mass culture communication modes in micro-era together with micro-film. The information received exists in the form of fragmentization, which can form very good promotion function for the emergence and development of micro-film. Micro-film is short and concise. It is relatively simple in the form. It exactly complies with audiences' demand for information fragmentization in communication and time. Modem communication media with mobile new media and network bring the carrier make micro-film communication form transform to be audience-centered. In this way, audiences will master more speaking right. In the past, the relationship between television and communication subject was mutually contradictory in terms of media feature, but this one-way communication way has been thoroughly broken in network era. It can boost participation and interaction of vast audiences in the communication process. In other words, micro-films can gain further deep development under diversified situation, show more contents and create greater value with new thought. The author believes that under the concerted effort of numerous micro-film art creators, Chinese micro-film will own brands with distinct characteristics in the near future and can achieve diversification and then drive synergetic development of contemporary culture and economy.

\section{Main idea of micro-film art creation}

Considering micro-film is one of new development modes of films, micro-film will certainly own the nature and features of films. In this regard, artistry which mainly expounds the meaning at spiritual level rather than singly considering economic interest is the idea of micro-film art creation. This meanwhile is also a brand-new idea that creators and vast audiences can accept. Micro-film art creation aims to dig application skills and techniques of spirit and emotion creators want to convey. Meanwhile, it is still necessary to depend on art features of micro-films to reflect art features of the emotion of vast audiences. This is the significance of micro-film creation and also reveals deep-level 
art features of micro-films. Artistry of micro-films often requires applying rhythm of images and voices to show certain logic. In current all kinds of micro-films, some voices seem to be very dull and lack sufficient expressive force, which thus affects logic development. In this way, it is hard for audiences to empathize with others after appreciating micro-films and keep calm emotion all the time.

\section{Micro-film owns creative concept of colourism}

In micro-film, since the story line develops continuously, shot application means and images also transform so that visual impression of micro-film is shown under the precondition of mutual adaptation with the story line. Further, the visual effect improves. An important constituent of micro-film is image and color. Hence, in micro-film art creation process, image color should not just adapt story background, but also should be blended in visual effect. Image color can not merely make the style and sentiment of micro-films more color and richer, but also better boost visual art effect of micro-films. In micro-film image color design process, various application rules should be followed, and the features should be stressed. Design of corresponding image color in micro-film can further enhance the impression of vast audiences and then trigger audiences' resonance. In this way, art features of micro-film can well improve and better and after development of micro-films can be promoted.

\section{Micro-film owns creative concept of realism}

Realism creation idea of micro-film is usually reflected in the following two aspects: 1) micro-film often applies an incident to explore and analyze social issues and pays much attention to observing inner world of modern people; 2) micro-film is closely related to daily life of modern people, and many micro-film works focus on reflecting the life of nobody of different types. Just because micro-film attaches great importance to the life and dream of nobody and common people and shows inner driving force of common people, micro-film must give full play to various advantages and more overall display dribs and drabs in life, contact the deepest heart of all appreciators, and focus on exploring spiritual world hidden in the heart of modern people. Only in this way, micro-film can be really called film performance art. It thus can be seen that concerning the present and showing real life are outstanding advantages of micro0film creation. Besides, these are also social sense of responsibility that micro-film must undertake.

\section{Micro-film owns creative concept of structuralism}

The structure of film works is plot setting, i.e. cutting and layout of film creation elements. Micro-film structure often generates some special requirements due to time and space restrictions. For structure type of micro-film, micro-films may be classified into closed creation structure and open creation structure. Micro-film will not use figure exhibition structure, because the problems shown become broader and further approach real life of common people, and the figures involved are many. Thus, figure exhibition structure is not applicable to micro-film. The author concludes the exploration of micro-film structure as follows: firstly, suspense and foreshadowing should be arranged. Generally speaking, suspense and foreshadowing coexist. Foreshadowing often underlies suspense and sometimes serves as the suspense. To facilitate drama to move towards the climax and rationally foreshadow for next-step development, suspense and foreshadowing can be applied together. Secondly, there should be such deconstruction form from absurd to reason. Reason and absurd often reflect two different constituent parts of the same problem, which is usually reflected in story line deconstruction. In other words, some novel and unique events must be introduced to let audiences consider the story is very rare and even feel preposterous. Then, dramatic conflict means can be applied for transformation so as to make story line more rational. Finally, a huge contradictory deconstruction form from discovery to sudden change is needed. When the story line in the micro-line develops to corresponding degree and approaches the climax, audiences can often feel the story fast forms a sudden change and the plot also develops to the climax from original foreshadowing. Later, the plot will sharply change from the climax stage. The above whole process is the core link of micro-film art creation design. 


\section{Conclusion}

In conclusion, micro-film still belongs to a fresh thing and is in the fast development stage. There are still many difficulties and challenges. How to keep art charm and aesthetic characteristics of micro-film, construct more scientific and executable micro-film industrial standards and further expand commercial development space of micro-films needs to be deeply considered. Although micro-film is still faced with numerous difficulties, micro-film will certainly find out a suitable development path in new media era as Chinese micro-film creation continuously improves and innovates.

\section{References}

[1] Li Rongrong, Exploration of micro-film narrative strategy in communication field. Southeast Communication, 2011 (12).

[2] Nie Wei, Micro-film: evolution, opportunity and challenge. Journal of Shanghai University (Social Sciences), 2012 (4).

[3] Wang Zhenxin, Han Qiang, On micro-film art creation. Chinese Film Market, 2013 (1).

[4] Shi Li, Art features of micro-film creation. Science \& Technology for China, 2013 (14).

[5] Zhang Qiaolun, Shi Zhuqing, Micro-film creation under new medial background. Science \& Technology for China, 2014 (2).

[6] Wan Zhongjie, Zhang Ying, Essence and art creation of micro-film. Family of the Drama, 2015 (1). 